Батаев Д.К-С., Газиев М.А., МажиевХ.Н.

ВЫБОР ТЕОРИИ ПОЛЗУЧЕСТИ ДЛЯ ОЦЕНКИ ДЛИТЕЛЬНОГО ДЕФОРМИРОВАНИЯ МЕЛКОЗЕРНИСТОГО АВТОКЛАВНОГО ЯЧЕИСТОГО БЕТОНА С УЧЕТОМ ФАКТОРА КАРБОНИЗАЦИИ

\author{
Bataev D.K-S., Gaziev M.A., Majiev H.N.
}

\title{
CHOICE THEORY OF CREEP DEFORMATION FOR EVALUATION OF LONG FINE-GRAINED AUTOCLAVED AERATED CONCRETE IN VIEW OF FACTORS CARBONIZATION
}

Приведены экспериментальныле данные о влиянии возраста автоклавного ячеистого бетона с учетом и без учета фактора его карбонизации на изменение физико-механических характеристик, а также на величину деформации ползучести и степени ее обратимости. Выявлено, что при решении прикладных задач теории ползучести для конструкиий из автоклавных ячеистых бетонов с учетом их карбонизачии от воздействия атмосферного углекислого газа, необходимо пользоваться теорией упруго-ползучего тела на основе функиии меры ползучести в форме, предложенной профессором С.В. Александровским.

Ключевые слова: теория ползучести, ячеистый бетон, деформирование, автоклавный бетон, карбонизачия.

Experimental data on the effect of the age of autoclaved aerated concrete with and without carbonation factor to change its physical and mechanical characteristics, as well as by the amount of creep deformation and degree of reversibility. It was found that the solution of applied problems creep theory for structures of autoclaved aerated concrete, in accordance with their carbonation from the effects of atmospheric carbon dioxide, it is necessary to use the theory of elastic-creeping body on the basis of function creep measures in the form proposed by prof. $S$.V. Alexandrovsky.

Key words: creep theory, cellular concrete, deformation, autoclave concrete, carbonation.

Введение. В условиях эксплуатации ячеистобетонные ограждающие конструкции испытывают воздействие углекислоты воздуха, концентрация которой в обычной атмосфере составляет около $0,03-0,05 \%$.

По данным Е.С. Силаенкова, в результате воздействия атмосферного углекислого газа в автоклавном ячеистом бетоне протекает реакция карбонизации, которая, со временем распространяясь по всей толщине изделия, изменяет химический и минералогический состав цементирующего камня, объем 
кристаллической части твердой фазы и приводит к возникновению микродефектов при химическом разложении гидросиликатов цементного камня на карбонаты кальция и гель кремнекислоты; развивается карбонизационная усадка, снижаются прочность и модуль упругости бетона [8].

Проведенные ранее в Уральском Промстрой НИИпроекте исследования доказали о существенном влиянии степени карбонизации на величину и характер развития деформации ползучести автоклавного ячеистого бетона [5].

Расчет бетонных и железобетонных конструкций с учетом длительных процессов осуществляется на основе одной из трех теорий ползучести бетона: упругой наследственности, теории старения и теории упруго-ползучего тела (наследственной теории старения). Эти теории исходят из одних и тех же предпосылок, но по-разному оценивают процесс старения бетона обычного твердения, который выражается в росте его прочности и модуля упругости во времени и в уменьшении деформации ползучести с увеличением возраста бетона к моменту загружения. Существующие теории ползучести бетона отличаются также и различным подходом к вопросу обратимости деформаций ползучести при частичной или полной разгрузке, что находит свое выражение в различной физической и математической интерпретации этого вопроса [1, 3 , 10].

Постановка задачи. В настоящей статье приводятся экспериментальные данные о влиянии возраста карбонизированного и некарбонизированного мелкозернистого автоклавного ячеистого бетона на изменение его физикомеханических характеристик и величину деформаций ползучести, а также степени обратимости деформаций ползучести при различных сроках воздействия длительной нагрузки, с целью выяснения, какая из существующих теорий ползучести наиболее правильно оценивает характер длительного деформирования мелкозернистого автоклавного ячеистого бетона с учетом фактора его полной карбонизации.

Методы испытаний. С.В. Александровский и В.И. Скатынский для расчета ячеистобетонных конструкций при действии длительной нагрузки рекомендуют использовать как теорию упруго-ползучего тела, так и теорию упругой наследственности, исходя из особенностей решаемых задач [2,9].

Так, учитывая довольно большую степень обратимости деформаций ползучести автоклавных ячеистых бетонов при сравнительно небольших сроках загружения (при $(\mathrm{t}-\tau)=100$ суток, степень обратимости составляет 80-90\%) теория упругой наследственности дает лучшие результаты при решении задач с напряжениями, возрастающими во времени, а также при расчете напряженного состояния, вызываемого напряжениями, сравнительно быстро изменяющимися во времени по произвольному закону.

Однако, при решении релаксационных задач с большой продолжительностью, теория упругой наследственности будет давать значительные погрешности в связи с тем, что она переоценивает обратимость деформаций ползучести ячеистых бетонов. Для решения таких задач, по мнению авторов $[2,9]$, необходимо пользоваться теорией упруго-ползучего тела. 
Изменение с течением времени прочности и модуля упругости автоклавных ячеистых бетонов без учета фактора карбонизации изучалось С.В. Александровским [2], И.Я. Кривицким, Н.И. Левиным и А.Н. Счастным [6], В.И. Скатынским [9].

С.В. Александровским для оценки изменения физико-механических свойств ячеистых бетонов с течением времени испытывались изолированные образцы из газо - и газозолобетонов плотностью соответственно 956 и 872 кг/ $\mathrm{M}^{3}$. Прочность и модуль упругости бетонных образов определялись через 4 , 7, 14, 28 и 74 суток. На протяжении опытов прочностные характеристики и модуль упругости исследованных бетонов оставались практически постоянными [2].

По данным [6], кубиковая прочность образцов из ячеистого бетона плот-

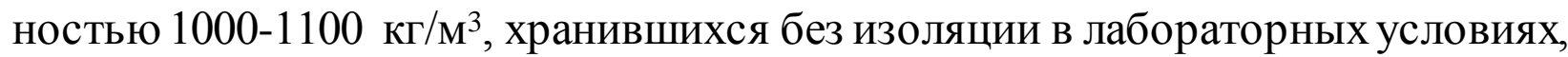
увеличилась примерно на 25\% в течение первых трех месяцев. Эти изменения связаны, в основном, с высыханием ячеистых бетонов и фактически прекращаются, когда бетон достигает равновесной влажности.

В дальнейшем образцы хранились в течение 15 лет при температуре 18$22^{\circ} \mathrm{C}$ и относительной влажности воздуха 40-60\%. Однако, в этих условиях процесс карбонизации в автоклавном ячеистом бетоне почти не происходит. Поэтому результаты опытов оказались идентичными с опытами на изолированных образцах, а именно, прочность и модуль упругости автоклавных ячеистых бетонов оставались неизменными.

К аналогичному выводу о постоянстве призменной прочности и модуля упругости образцов-призм из автоклавного газосиликата плотностью 950 кг/Mㄹ при сходной методике испытаний пришел В.И. Скатынский [9].

Результаты эксперимента и их обсуждение. Нами испытывались образцы размером 10х10х40 см из мелкозернистого газозолобетона автоклавного твердения плотностью 600 кг $/ \mathrm{M}^{3}$, изолированные от высыхания при 10\%ной влажности до и после карбонизации в возрасте 1, 30, 60, 90, 180 и 360 суток с момента окончания их полной карбонизации. В табл. 1 приведены данные об изменении физико-механических свойств газозолобетона с течением времени. Они показывают, что прочностные и деформативные свойства некарбонизированного бетона в течение 360 суток практически оставались постоянными. В карбонизированном бетоне в течение первых 3 месяцев произошло увеличение его кубиковой и призменной прочности соответственно на 19,6 и $22,3 \%$, а модуль упругости увеличился примерно на $18 \%$.

Качественно подобный характер изменения прочности и модуля упругости карбонизированных мелкозернистых ячеистых бетонов наблюдался и в исследованиях Е.С. Силаенкова [8], В. Лаха [7].

Согласно этим исследованиям можно предположить, что полученные нами данные об увеличении со временем прочности и модуля упругости изолированных после полной карбонизации образцов связаны с конструктивными процессами, происходящими в структуре бетона за счет перекристаллизации и стабилизации продуктов карбонизации. 
Таблица 1 - Изменение физико-механических характеристик мелкозернистого ячеистого бетона во времени

\begin{tabular}{|c|c|c|c|c|c|c|c|c|}
\hline \multirow{2}{*}{$\begin{array}{l}\text { Вид } \\
\text { бетона }\end{array}$} & \multirow{2}{*}{$\begin{array}{c}\text { Физико- } \\
\text { механические } \\
\text { характеристики }\end{array}$} & \multirow{2}{*}{$\begin{array}{c}\text { Размеры } \\
\text { опытных } \\
\text { образцов, см } \\
\end{array}$} & \multicolumn{6}{|c|}{ Возраст бетона, сутки } \\
\hline & & & 1 & 30 & 60 & 90 & 180 & 360 \\
\hline \multirow{3}{*}{1} & $\begin{array}{c}\text { Кубиковая } \\
\text { прочность, МПа }\end{array}$ & $10 \times 10 \times 10$ & 3,63 & 3,66 & 3,65 & 3,68 & 3,66 & 3,64 \\
\hline & $\begin{array}{c}\text { Призменная } \\
\text { прочность, Мпа }\end{array}$ & $10 \times 10 \times 40$ & 3,47 & 3,52 & 3,50 & 3,56 & 3,55 & 3,53 \\
\hline & $\begin{array}{c}\text { Модуль } \\
\text { упругости, } \\
\mathrm{Eb}_{\mathrm{b}} 10^{-3}, \text { МПа }\end{array}$ & $10 \times 10 \times 40$ & 2,21 & 2,24 & 2,22 & 2,23 & 2,23 & 2,24 \\
\hline \multirow{3}{*}{2} & $\begin{array}{c}\text { Кубиковая } \\
\text { прочность, МПа }\end{array}$ & $10 \times 10 \times 10$ & 2,43 & 2,50 & 2,85 & 3,02 & 3,04 & 3,00 \\
\hline & $\begin{array}{c}\text { Призменная } \\
\text { прочность, МПа }\end{array}$ & $10 \times 10 \times 40$ & 2,06 & 2,30 & 2,57 & 2,65 & 2,66 & 2,65 \\
\hline & $\begin{array}{c}\text { Модуль } \\
\text { упругости, } \\
\mathrm{E}_{\mathrm{b}} \times 10^{-3}, \text { МПа }\end{array}$ & $10 \times 10 \times 40$ & 0,940 & 0,992 & 1,054 & 1,108 & 1,110 & 1,110 \\
\hline
\end{tabular}

Примечание: 1 - некарбонизированный газозолобетон; 2 - то же, карбонизированный (возраст бетона отсчитывается с момента окончания процесса карбонизации)

Влияние возраста бетона в момент его загружения на развитие деформаций ползучести автоклавных ячеистых бетонов исследовалось в работах [2,9].

С.В. Александровский изучал ползучесть изолированных газо- и газозолобетонных образцов, загруженных в возрасте от 4 до 74 суток. Согласно его данным, начиная с возраста бетона, равного 14 суткам, деформация ползучести ячеистых бетонов оказалась независимо от возраста загружения практически одинаковой [2].

В.И. Скатынским [9], Л.М. Красновым и Н.И. Левиным изучалось влияние возраста бетона на ползучесть пено- и газосиликатных неизолированных образцов после достижения бетоном влажности, равной 2-3\% по массе.

При такой влажности бетона углекислый газ воздуха практически не взаимодействует с ним. Поэтому в этих работах деформация ползучести ячеистого бетона оказалась независимой от его возраста в момент загружения, как и для изолированных образцов.

Полученные Л. Раннамяги опытные данные свидетельствуют о том, что возраст силикатного ячеистого бетона мало сказывается на развитии его деформаций ползучести.

Таким образом, по опубликованным экспериментальным данным, ползучесть образцов из мелкозернистых автоклавных ячеистых бетонов, изолированных от высыхания, а также образцов, хранящихся в условиях отсутствия влияния углекислого газа воздуха на бетон, не зависит от возраста бетона в момент его загружения. 
Проведенные нами исследования деформаций ползучести некарбонизированных и изолированных при 10\%-ой влажности образцов из мелкозерни-

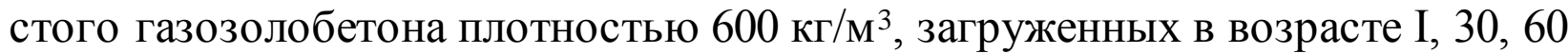
и 90 суток, как видно из рис.1.б, также указывают на независимость величины ползучести от возраста мелкозернистого ячеистого бетона.

В то же время, кривые деформаций ползучести полностью карбонизированного бетона (рис.1.а) при идентичных условиях испытания, показывают качественную и количественную разницу в процессах ее развития при загружении образцов в разные сроки после карбонизации, по сравнению с некарбонизированным бетоном.

Исследование влияния фактора карбонизации на ползучесть автоклавного мелкозернистого ячеистого бетона проводилось на основе специальной методики, разработанной одним из авторов данной статьи [4].

В карбонизированном газозолобетоне, как следует из рис.1.а, с повышением возраста к моменту нагружения значительно уменьшается явление ползучести, что свойственно, как известно, «молодому» бетону обычного твердения.

Аналогия между карбонизированным автоклавным мелкозернистым ячеистым бетоном и бетоном обычного твердения в раннем возрасте объясняется тем, что как у того, так и у другого бетона в твердой фазе велико содержание гелевидной части. Преобразование этой гелевидной части, уменьшение ее объема, огрубление геля вызывают при нагружении сходные явления у этих бетонов.

Значительное изменение геля происходит в короткие сроки. Этим и объясняется большое влияние возраста бетона в момент его загружения на ползучесть автоклавного карбонизированного газозолобетона и бетона обычного твердения в раннем возрасте.

У автоклавного некарбонизированного мелкозернистого газозолобетона так же, как у «старого» бетона обычного твердения, гелевидная часть твердой фазы мала и поэтому возраст бетона не оказывает существенного влияния на величину деформаций ползучести этих бетонов.

Данные о влиянии возраста мелкозернистого газозолобетона на изменение его физико-механических характеристик (табл. 1) и деформаций ползучести (рис. 1) с учетом и без учета фактора карбонизации говорят о том, что для карбонизированного автоклавного мелкозернистого ячеистого бетона окажутся подходящими представления о процессе ползучести, принятые в теории упруго-ползучего тела, а для некарбонизированного - представления о процессе ползучести, принятые в теории упругой наследственности.

На рис.1.а показано сравнение экспериментальных кривых удельных относительных деформаций ползучести для карбонизированного мелкозернистого газозолобетона $\mathrm{C}(\mathrm{t}, \tau)$, полученных в опыте, с соответствующими теоретическими кривыми, рассчитанными на основе теории упруго-ползучего тела:

$$
C(t, \tau)=\varphi(t)-\psi(\mathrm{t}) \frac{e^{\gamma_{1} \tau}-A_{1}}{e^{\gamma_{1} t}-A_{1}}-\Delta(\tau) \mathrm{e}^{-\alpha(\mathrm{t}-\tau)},
$$


со значениями параметров: $\psi(\mathrm{t})=\varphi(\mathrm{t})-\Delta(\mathrm{t}) ; \mathrm{A}_{1}=0,8 ; \gamma_{1}=0,023$ (сут. $)^{-1} ; \alpha$ $=5(\text { сут. })^{-1}$;

$(\mathrm{t}-\tau)$ - длительность наблюдений, сут.

a)

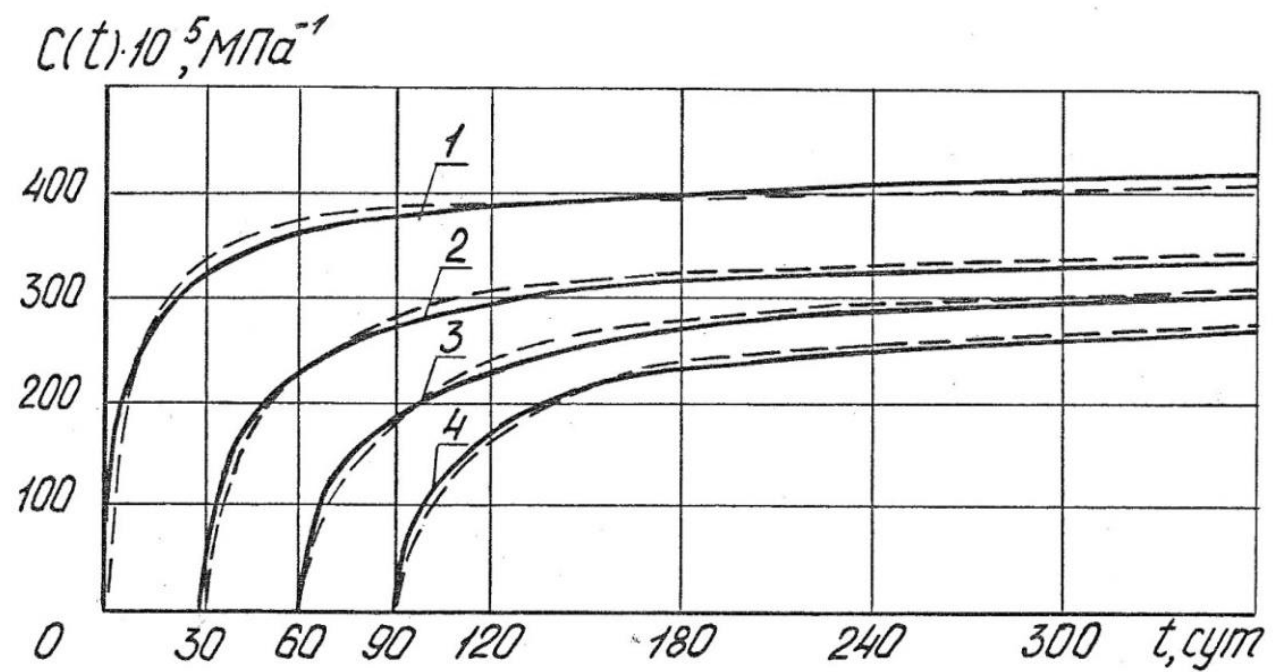

б)

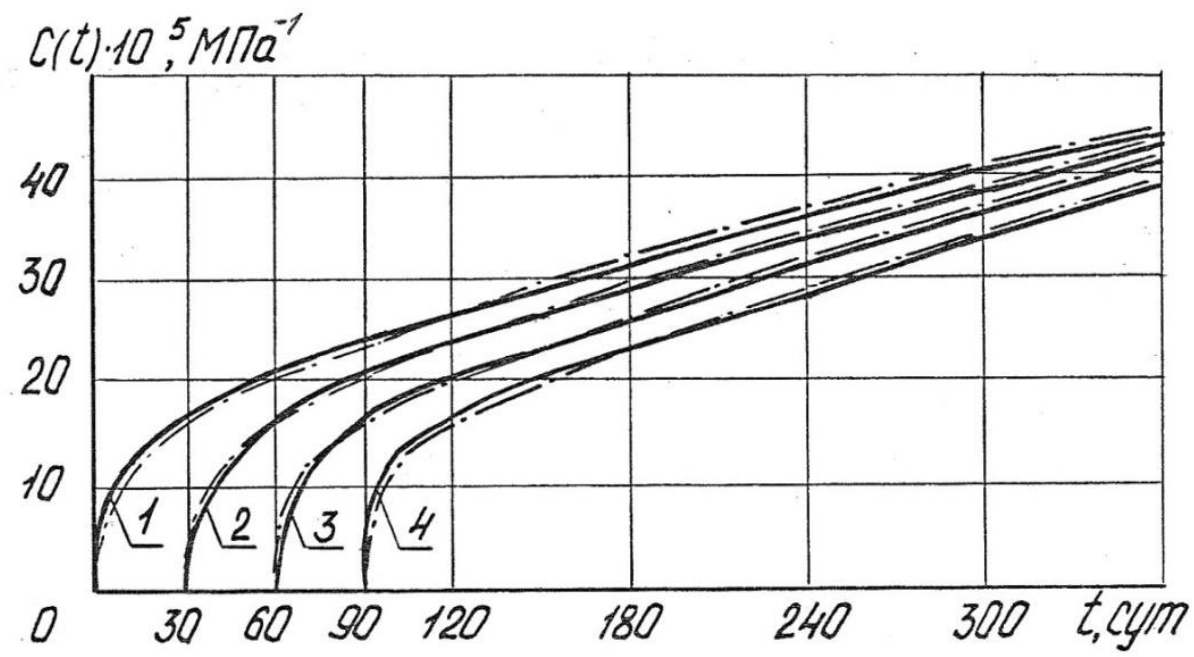

Возраст бетона: I - I сут.; 2 - 30 сут.; 3 - 60 сут.; 4 - 90 сут.

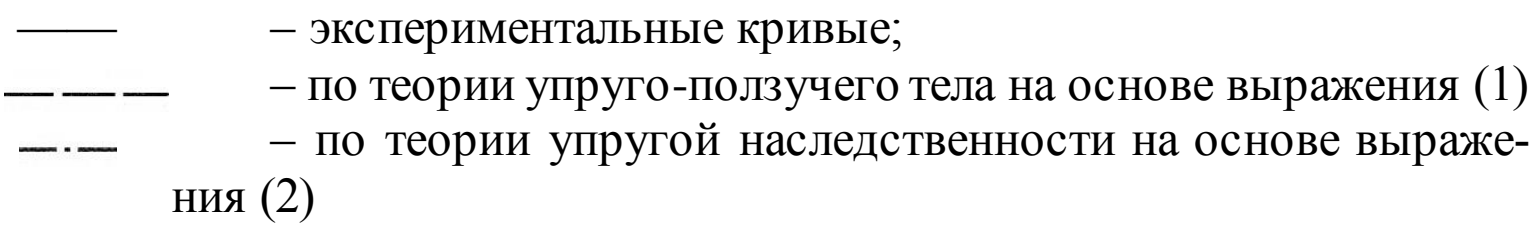

Рисунок 1 - Ползучесть карбонизированного (а) и некарбонизированного (б) мелкозернистого газозолобетона, загруженного в разных возрастах

Функции $\varphi(\tau)$ и $\Delta(\tau)$, т.е. функция изменения предельных мер ползучести и соответственно функция изменения во времени быстро натекающих деформаций ползучести после загрузки, аппроксимировались суммами простых экспоненциальных функций и равны: 


$$
\begin{gathered}
\varphi(\tau)=\left(280+222,2 \cdot \mathrm{e}^{-0,040 \tau}-99,2 \cdot \mathrm{e}^{-0,059 \tau}\right) \times 10^{-5}(\mathrm{M \Pi а})^{-1} ; \\
\Delta(\tau)=\left(20+58,5 \cdot \mathrm{e}^{-0,043 \tau}\right) \times 10^{-5}(\mathrm{M \Pi a})^{-1}
\end{gathered}
$$

где $\tau$ - возраст бетона, сут.

На рис.1.б приведено сравнение экспериментальных кривых мер ползучести для некарбонизированного мелкозернистого газозолобетона с соответствующими теоретическими кривыми, рассчитанными на основе теории упругой наследственности:

$$
C(t-\tau)=A_{2}\left[1-e^{-\gamma_{2}(t-\tau)}\right]+A_{3}\left[1-e^{-\gamma_{3}(t-\tau)}\right],
$$

где $\mathrm{A}_{2}=48,5 \cdot 10^{-5}(\mathrm{M \Pi a})^{-1} ; \mathrm{A}_{3}=11,5 \cdot 10^{-5}(\mathrm{M \Pi a})^{-1}$;

$\gamma_{2}=0.0031$ (сут. $)^{-1} ; \quad \gamma_{3}=0.09$ (сут.) $)^{-1}$

$(\mathrm{t}-\tau)$ - длительность наблюдений, сут.

Параметры $\alpha, \gamma_{1}, \mathrm{~A}_{1}$ и функции $\varphi(\mathrm{t})$ и $\Delta(\tau)$ в формуле (1), а также параметры $\gamma_{2}, \gamma_{3}$ и $\mathrm{A}_{2} \mathrm{~A}_{3}$ в формуле (2) подбирались из условия наилучшего соответствия экспериментальным данным по методу наименьших квадратов.

Из сопоставления экспериментальных и теоретических кривых мер ползучести, приведенных на рис.1 (а и б), видно, что подобранные аналитические зависимости достаточно точно описывают экспериментальные данные. Максимальное расхождение экспериментальных данных и значений мер ползучести, рассчитанных по формулам (1) и (2) составляло 10-15\%.

Полученные нами экспериментальные кривые о влиянии возраста карбонизированного и некарбонизированного мелкозернистого газозолобетона на их ползучесть (рис.1) были аппроксимированы аналитическими выражениями для меры ползучести «стареющего» и «нестареющего» бетонов в форме, предложенной профессором С.В. Александровским [3].

Исследования обратимости деформации ползучести проводились на полностью карбонизированных и некарбонизированных образцах-призмах размерами 10x10x40 см из мелкозернистого газобетона плотностью 600 и 700 $\kappa \Gamma / \mathrm{M}^{3}$. Для исключения погрешностей, связанных с неаддитивностью усадки и ползучести, образцы испытывали в изолированном виде при влажности бетона равной $10 \%$.

Напряжение загрузки в призмах составляло 0,3 от призменной прочности некарбонизированного и карбонизированного мелкозернистого бетона. Всего было загружено 48 образцов-близнецов (по 24 шт. для каждого вида бетона). После 30, 90 и 180 сут. воздействия нагрузки по шесть образцов разгружались для определения обратимости деформаций ползучести. При этом по шесть образцов оставляли под нагрузкой для определения ползучести.

Об этом свидетельствуют также опытные данные о степени обратимости деформаций ползучести мелкозернистых ячеистых бетонов, полученных нами с учетом и без учета их карбонизации (рис.2).

Как показывают опытные кривые (рис.2), для полностью карбонизированных мелкозернистых ячеистых бетонов характерна меньшая степень обра- 
тимости деформаций ползучести. Обратные деформации ползучести карбонизированных образцов из газобетона плотностью 700 кг/м³, разгруженных через 30, 90 и 180 суток, составили соответственно 43, 35 и 22\% при длительности наблюдения, равной 540 суткам после разгрузки.
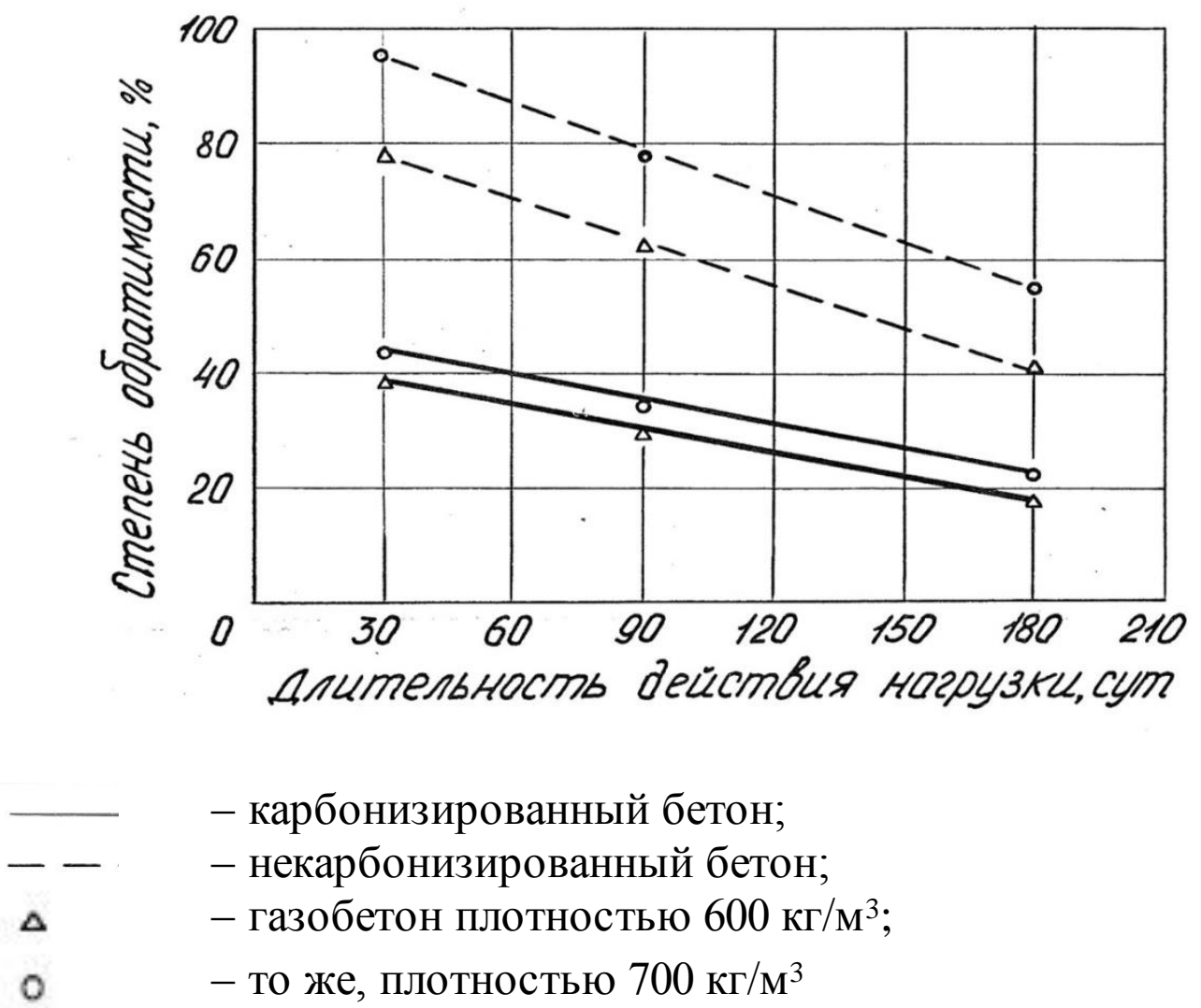

Рисунок 2 - Влияние длительности действия нагрузки на обратимость деформаций ползучести мелкозернистого ячеистого бетона с различной плотностью

Для этих же сроков степень обратимости деформаций ползучести серии образцов из некарбонизированного бетона составила 93, 78 и 56\%. Меньшая степень обратимости деформаций ползучести карбонизированного бетона по сравнению с некарбонизированным объясняется тем, что твердая фаза карбонизированного бетона состоит из геля кремнекислоты и кристаллической части, а твердая фаза некарбонизированного бетона является полностью кристаллической с той или иной степенью закристаллизованности.

Таким образом, для расчета длительных деформаций конструкций из автоклавного мелкозернистого ячеистого бетона с учетом его полной карбонизации при воздействии атмосферного углекислого газа следует пользоваться функцией меры ползучести $\mathrm{C}(\mathrm{t}, \tau)$ на основе теории упруго-ползучего тела в форме (1), предложенной профессором С.В. Александровским.

\section{Вывод.}

1. Физико-механические свойства, а также деформация ползучести изолированного от высыхания некарбонизированного мелкозернистого ячеисто- 
го бетона не зависят от его возраста. Для полностью карбонизированного и изолированного от высыхания мелкозернистого ячеистого бетона с ростом его возраста (возраст отсчитывается с момента окончания процесса карбонизации) наблюдается некоторое увеличение прочности, модуля упругости и уменьшение деформаций ползучести бетона.

2. Карбонизация мелкозернистого автоклавного ячеистого бетона снижает степень обратимости его деформаций ползучести. При этом величина обратимости деформаций ползучести мелкозернистого ячеистого бетона с учетом и без учета его карбонизации уменьшается с увеличением длительности действия нагрузки, а также с понижением плотности бетона.

3. Экспериментальные кривые мер ползучести при различном возрасте карбонизированного мелкозернистого ячеистого бетона хорошо согласуются с соответствующими теоретическими кривыми, вычисленными по теории упруго-ползучего тела на основе функции меры ползучести в форме, предложенной профессором С.В. Александровским. Это позволяет нам рекомендовать при решении прикладных задач теории ползучести для конструкций из мелкозернистых ячеистых бетонов, с учетом фактора карбонизации, пользоваться теорией упруго-ползучего тела.

\section{Библиографический список:}

1. Александровский С.В., Бондаренко В.М., Прокопович И.Е. Приложение теории ползучести к практическим расчетам железобетонных конструкций // Ползучесть и усадка бетона и железобетонных конструкций. - М. - 1976. C.256-301.

2. Александровский С.В., Данилов Б.П., Багрий Э.Я. Исследование ползучести ячеистого бетона//Ползучесть и усадка бетона: тезисы докладов / НТО стройиндустрии УССР и НИИСК Госстроя СССР. - Киев.- 1969. - С.5-12.

3. Арутюнян Н.Х., Александровский С.В. Современное состояние развития теории ползучести бетона//Ползучесть и усадка бетона и железобетонных конструкций. - М. - 1976. - С.5-96.

4. Газиев М.А. Методика определения деформаций ползучести автоклавных ячеистых бетонов с учетом их старения от действия углекислого газа // Долговечность конструкций из автоклавных бетонов. - Таллин. - 1984. - Ч І. C.167-169.

5. Газиев М.А. Деформативность ячеистого бетона при длительном сжатии с учетом степени его карбонизации // Ячеистый бетон и ограждающие конструкции из него. - М. - 1985. - С.65-68.

6. Кривицкий М.Я., Левин Н.И., Счастный А.Н. Ползучесть автоклавных ячеистых бетонов с учетом некоторых технологических факторов // Производство и применение изделий из ячеистых бетонов. - М., 1968. - С.105-120.

7. Lach V. Problemy karbonatuce lehkych beton. - Stavebui vyzkum, 1971, 15, № 4, p.1-7.

8. Силаенков Е.С. Долговечность изделий из ячеистых бетонов. - М.: Стройиздат, 1986. - $176 \mathrm{c}$. 
9. Скатынский В.И., Крумелис Ю.В. К выбору теории ползучести для описания длительного деформирования ячеистых силикатных бетонов // Ползучесть и усадка бетона: Тезисы докладов, подготовленные Украинским республиканским правлением НТО стройиндустрии и НИИСК Госстроя СССР. Киев. - 1969. - С.155-164.

10. Тамразян А.Г., Есаян С.Г. Механика ползучести бетона. - М.: МГСУ, 2012. $-524 \mathrm{c}$.

УДК 699841

Зайнулабидова Х.Р., Курбанов И.Б.

РАСЧЕТ ОПТИМАЛЬНОГО УРОВНЯ НАДЕЖНОСТИ И АНТИСЕЙСМИЧЕСКОГО УСИЛЕНИЯ КОНСТРУКЦИЙ ЗДАНИЙ

\section{Zajnulabidova H.R., Kurbanov I.B.}

\section{CALCULATING THE OPTIMUM LEVEL OF RELIABILITY AND ANTI-SEISMIC REINFORCEMENT OF STRUCTURES OF BUILDINGS}

Дана постановка задачи оптимизационного расчёта конструкций с учётом сейсмической опасности. Представлены условия оптимизации, основанные на вероятностно-экономическом критерии. Для зданий с возможными неэкономическими последствиями введено ограничение на вероятность отказа, величина которой определяется исходя из ограничения нематериальных потерь. Сейсмическую опасность территории предлагается оченить в виде прогнозируемых за срок службы здания воздействий с соответствующиими вероятностями повторяемости и спектральными параметрами или в виде расчётной акселерограммы. Реализуемость методики показана на примере большепролётного здания со стальными колоннами составного двутаврого сечения.

Ключевые слова: сейсмическое воздействие, здания и сооружения, условия оптимизации, вероятностно-экономический критерий, вероятность отказа, оптимальный коэффициент усиления, оптимальная надёжность.

Given problem optimization calculation of structures considering seismic hazard. Optimization conditions are presented based on probabilistic and economic criteria. For buildings with possible non-economic effects of a restriction on probability of failure, the amount of which is determined on the basis of the limitations of intangible losses. Seismic risk territories to evaluate as projected over the life- 